Observatório de

Inovação do Turismo

BRASIL

Revista Acadêmica

ISSN 1980-6965

www.ebape.fgv.br/revistaoit

Sensacional!

\title{
A gastronomia como diferencial de hospitalidade e entretenimento: uma análise virtual
}

The gastronomy as differential hospitality and entertainment: virtual analysis

Diego César Terra de Andrade

\section{Resumo}

O turismo convencional tem perdido espaço para um novo turismo: associado aos serviços informatizados e de ponta, como lazer, entretenimento, cultura, mídia, gastronomia, moda, alta segmentação, minorias em geral. Neste trabalho, objetiva-se identificar qual a importância que, nos meios de hospedagem, se dá à gastronomia como diferencial de hospitalidade e entretenimento. Com isso, por meio de pesquisa documental - exploratória de amostra não probabilística -, realizada com os participantes da Associação Roteiros de Charme, concluiuse que a gastronomia se faz presente e é importante na divulgação do mix de produtos e serviços oferecidos pelas organizações.

Palavras-chave: gastronomia, hospitalidade, entretenimento 


\section{Abstract:}

Conventional tourism has given way to a new tourism. A related tourism services and computerized edge as leisure, entertainment, culture, media, food, fashion, high segmentation, minorities in general. This study aims to identify how important the lodging facilities give food as differential hospitality and entertainment. Thus, through documentary research, exploratory non-probability sample conducted with participants of the Association Tours Charming, it was concluded that the food is present and important in spreading the mix of products and services offered by these organizations.

Key words: catering, hospitality, entertainment

\section{Introdução}

Observa-se que, na atualidade, a maior sensação em termos de crescimento e de empregabilidade no mundo (e, é claro, no Brasil) é o setor de serviços. Os serviços ao cliente vêm demonstrando um enorme potencial para que as organizações possam construir vantagens competitivas sustentáveis, principalmente quando o diferencial de mercado surge da ênfase ao contato direto da empresa com os consumidores. Não há como deixar de prestar atenção num setor que tem demonstrado bons resultados com consequente aumento do Produto Interno Bruto (PIB). Segundo o Instituto Brasileiro de Estatística (IBGE), no Brasil, em 2008, o PIB representou 53 \% da riqueza produzida no País (tendência clássica no desenvolvimento das nações) contra $10 \%$ do setor de agropecuária e $37 \%$ do setor da indústria (IBGE, 2009).

No setor de serviços, o segmento do turismo é um dos que mais crescem na economia mundial e, segundo a Organização Mundial de Turismo (OMT), é a atividade que movimenta 53 diferentes setores da economia (ANDRADE, 2004). No segmento de turismo, pode-se destacar a prestação de serviços hoteleiros e 
suas variantes de turismo, como o acadêmico, o de compras, o de lazer, o de negócios, o rural, o ecológico, o médico, o náutico.

O turismo de lazer detém uma importante fatia do mercado hoteleiro, e pesquisas realizadas por diferentes autores demonstram a importância da alimentação para esse tipo de turismo. Krippendorf (2000) relata que, entre outras razões, comer bem é uma das motivações para 35\% dos turistas; outro resultado significativo é apontado por Goeldner (2002), em estudo realizado nos Estados Unidos, quando identificou que, para $86,2 \%$ dos entrevistados (turistas), uma das atividades referidas como preferência em viagens é a de fazer refeições em restaurantes.

Sobre a relação da gastronomia como diferencial de hospitalidade e lazer, e a forma como ela vem sendo disponibilizada pelos modernos canais de comunicação (diante da insuficiência de estudos concluídos e do interesse por parte do pesquisador), tem-se o seguinte questionamento: Qual a importância que, nos meios de hospedagem, se dá à gastronomia, como diferencial de hospitalidade e entretenimento, e se essa variável vem sendo explorada pelas organizações na rede mundial de computadores?

Destarte, objetiva-se, por meio deste estudo, identificar, com base na pesquisa documental (método) em websites, qual a importância que, nos meios de hospedagem, se dá à gastronomia como diferencial de hospitalidade e entretenimento, de modo a ser percebida nos meios de comunicação das destinações turísticas.

Um fator determinante para avaliar a exploração da gastronomia por intermédio de sites informativos dos meios de hospedagem é que, segundo Trigo (1998), a facilidade de acesso a conhecimentos, por meio dos modernos canais de comunicação e informação, pelos quais as pessoas buscam cientificarse sobre diversificadas localidades e suas peculiaridades, age diretamente na motivação delas para viajar e conhecer "mais e mais" destinos turísticos, e, principalmente, mudanças culturais, como a busca pelo inusitado, autêntico e, 
ainda, a fuga do cotidiano, especialmente, em culturas diversas. Conclui-se, portanto, que essa seja uma etapa pela qual o turista passe antes de, efetivamente, realizar uma viagem real.

\section{Referencial Teórico}

"A tendência humana de compartilhar alimentos, a ideia básica de hospitalidade, teria se originado quando o homem desenvolveu a capacidade de matar grandes presas. Esse tipo de caça muitas vezes o forçava à associação." (FRANCO, 2001, p.21). Como não havia métodos de conservação, a caça devia ser consumida rapidamente, levando o homem a dividir o alimento, e surgiram então as primeiras noções de hospitalidade.

Quanto ao aparecimento de restaurantes, o objetivo inicial era o de, simplesmente, oferecer um alimento restaurador aos viajantes. Já o fenômeno da gastronomia nos meios de hospedagem teve início na Europa, quando, como exposto por Dias (2002), com base em um modelo operacional capaz de oferecer conforto, alta culinária e um serviço de qualidade, Cesar Ritz, dos Hotéis Ritz, teve a oportunidade de conhecer pessoas competentes em sua área, como o chef Auguste Escoffier, que, com sua culinária francesa, ajudou a introduzir, na Inglaterra, um novo conceito de restaurante, transformando-o de um meio de hospedagem num lugar de encontro social, que, posteriormente, se difundiu pelo mundo como modelo eficiente de diferenciação no setor.

A gastronomia, portanto, insere-se na atividade turística, pois o viajante necessita da alimentação, primeiramente, por um aspecto fisiológico, depois, porque alimentação é, também, fonte de prazer e experiência, que ocorre por meio da degustação de novos pratos e formas de preparo nos locais visitados (SCHREIBER, 2006).

Pensar a questão da realização da atividade turística na totalidade pode ser um exercício a ser feito pelos fornecedores de produtos e serviços turísticos 
de um destino - porque a atividade turística implica diversas cadeias de elementos que envolvem desejos, sentimentos, intenções e expectativas do consumidor que compra um produto sem antes tê-lo experimentado. No mesmo sentido, há também os fornecedores de produtos e serviços, que têm uma diversidade de elos (transporte, hospedagem, alimentação, atrações, etc.) necessários para a composição do produto e que, conjuntamente, precisam atender com qualidade ao esperado pelo cliente, antes, durante e ao final da viagem, preferencialmente superando expectativas.

De acordo com Vilarinho e Scorsato (2009), os produtos e os serviços turísticos apresentam as seguintes características:

1. Intangibilidade: não podem ser testados antes de serem comprados. Por exemplo, passageiros de empresas aéreas têm apenas uma passagem e a promessa de uma chegada segura ao destino. Para reduzir a incerteza, os compradores procuram sinais de qualidade de serviço. Tiram conclusões sobre a qualidade com base em tudo que puderem observar sobre o lugar, as pessoas, o equipamento, o material de comunicação e o preço. Nesse sentido, muitas empresas utilizam a tecnologia para tornar esses serviços tangíveis - por meio de animações digitais, fotos ou simplesmente realizando ações permanentes nas redes sociais -, o que reforça a existência dos serviços ofertados de fato.

2. Indivisibilidade: o produto é consumido e produzido simultaneamente, ou seja, serviços e produtos são inseparáveis da fonte que os presta e os produz. Essa característica confere vulnerabilidade ao produto turístico em consequência das variações existentes na prestação de serviços.

3. Variabilidade: a qualidade dos serviços depende de quem os proporciona e de quando, onde e como são proporcionados. Por exemplo, alguns hotéis oferecem melhores serviços que outros. Em 
um mesmo hotel, o funcionário que cuida do registro dos hóspedes é eficiente, enquanto outro funcionário, que trabalha no mesmo balcão, pode ser ineficiente. Mesmo a qualidade do serviço de um único funcionário varia de um dia para o outro, de acordo com a energia e a disposição do prestador no momento do contato com cada cliente.

4. Interdependência ou complementariedade: são necessários vários serviços para compor o produto turístico, como os de transporte, de hospedagem, de alimentação, além dos atrativos.

5. Perecibilidade: os serviços são perecíveis e não podem ser estocados para vendas ou uso futuro. A principal atenção em torno dessa característica deve ser na proporção entre demanda e oferta: quando a demanda é constante, o fato de os serviços serem perecíveis não causa maiores problemas; mas, quando é sazonal, os problemas podem ser graves.

Logo, na lógica da atividade turística, em que as diferenças e as especificidades de uma localidade são matérias-primas básicas, a relação que se estabelece entre o espaço e a produção gastronômica não é apenas incentivada, mas divulgada como forma de diferenciação de um destino turístico em relação a outro (SCHREIBER, 2006).

Assim, a alimentação agregada às viagens pode proporcionar ao turista conhecer a cultura da comunidade receptora, sua história, seus costumes e seus hábitos, podendo ser adotada como o diferencial que o turista procura e é um componente importante da hospitalidade à medida que atende e satisfaz o turista. Atualmente, a gastronomia é uma das atividades que mais contribuem para o desenvolvimento do turismo (BENI, 2003), pois, é também considerada como fonte de entretenimento e, em muitas regiões que não apresentam recursos ou atrativos, tem servido para atrair visitantes (LOOCWOOD; MEDLIK, 2003). 


\section{Metodologia}

A estrutura metodológica do presente trabalho caracteriza-se por apresentar pesquisa documental - exploratória de amostra não probabilística. Segundo Dencker (2002), "uma pesquisa documental utiliza material que não recebeu tratamento analítico, ou que pode ser reelaborado a qualquer momento". De acordo com Boyd Jr. e Westfall (1987), existem três linhas de ação para realizar estudos exploratórios: exame de dados secundários, investigação de indivíduos que podem dar informações sobre o assunto e análise de casos selecionados. Conforme Dencker (2002, p.179), "a amostragem não probabilística é aquela em que a possibilidade de se escolher determinado elemento do universo estabelecido é desconhecida", ou seja, o universo pesquisado não foi definido por probabilidade, e sim pelo bom senso do pesquisador. Portanto, diante da grande oferta de meios de hospedagem no País, optou-se por escolher (recorte da pesquisa) os integrantes da Associação Roteiros de Charme (objeto de estudo) para a realização da pesquisa.

$\mathrm{Na}$ Associação Roteiros de Charme, selecionam-se os meios de hospedagem considerando-se variados perfis e mantendo-se, assim, a independência e a personalidade de cada um. Entretanto são considerados essenciais alguns aspectos que todos devem ter em comum - como respeito às tradições de hospitalidade -, integrados a modernos conceitos de conforto e serviços.

Na Associação, objetiva-se que todas as expectativas dos hóspedes sejam plenamente atendidas, inclusive a gastronomia e o entretenimento. Os estabelecimentos pertencentes a Roteiros de Charme vão desde os refúgios ecológicos e as pequenas pousadas, cujos atendimentos são despretensiosos e singelos, até outros muito confortáveis, com estilos, requintes e serviços esmerados. 
Para orientar a escolha dos clientes, a Associação, em seu site, apresenta os meios de hospedagem divididos em quatro categorias distintas (ASSOCIAÇÃO ROTEIROS DE CHARME, 2009):

1. meio de hospedagem muito confortável, com instalações e serviços que atendam aos padrões de exigência da tradicional hotelaria internacional;

2. meio de hospedagem com conforto, bem equipado e aconchegante, com serviços esmerados, estilo e decoração requintada;

3. meio de hospedagem confortável, cuja decoração, serviço singelo e capricho refletem os costumes locais;

4. meio de hospedagem num paraíso ecológico, onde o serviço despretensioso e a decoração guardam identidade com a região.

Não basta, portanto, ter um meio de hospedagem para ingressar na Associação Roteiros de Charme, pois há uma filosofia comum a ser partilhada e exigências a serem atendidas. Os estabelecimentos associados têm os seguintes perfis (ASSOCIAÇÃO ROTEIROS DE CHARME, 2009):

1. Na diversificada listagem da Associação, há refúgios ecológicos, fazendas, hotéis confortáveis e alguns bastante sofisticados. Seja qual for a característica de estilo, o que importa é o charme conceito subjetivo que significa, genericamente, uma união entre bom gosto, atenção com detalhes, paixão de servir, conforto compatível com as expectativas dos hóspedes, localização privilegiada, construção adequada ao meio ambiente e à região, enfim, o conjunto de fatores que emprestam personalidade única ao local e ao próprio meio de hospedagem.

2. O meio de hospedagem deve estar em funcionamento há, pelo menos, dois anos sob a mesma administração, para que tenha consolidados o perfil e o padrão de serviços. Deverá ter de dez a 
sessenta apartamentos e/ou suítes e localização preferencial em pontos de interesse turístico, histórico ou ecológico.

Os cinquenta meios de hospedagem ${ }^{1}$ associados a Roteiros de Charmes estão distribuídos por quase todas as regiões do País (exceto a região norte) e presentes em 12 estados, o que mostra uma boa representatividade, como apresentado na Tabela 1.

\footnotetext{
${ }^{1}$ São eles: Anthurium Parque Hotel; Capim Limão - Hotel e Restaurante; Casa do Lago; Fazenda Capoava; Hospedaria Águas Claras; Hotel da Bocaina; Hotel Dolce Vita; Hotel Estalagem St. Hubertus; Hotel Fazenda Boa Esperança; Hotel Frontenac; Hotel Orixás; Hotel Parador Casa da Montanha; Hotel Pousada Canto das Águas; Hotel Recanto das Toninhas; Hotel Rosa dos Ventos; Hotel Santa Esmeralda; Hotel São Gotardo; La Hacienda Estalagem e Restaurante; Lake Resort Águas do Treme; Lavillette Pousada; Manary Praia Hotel; Pedra da Laguna Pousada e Spa; Pestana Hotéis - Angra dos Reis; Pousada Cravo e Canela; Pousada da Vigia; Pousada do Amparo; Pousada do Capitão; Pousada do Mondego; Pousada do Riacho; Pousada do Toque; Pousada Enseada das Garças; Pousada Estrela D’Água; Pousada Felíssimo; Pousada Ilha do Papagaio; Pousada Les Roches; Pousada Pitinga; Pousada Porto Imperial; Pousada Quinta dos Pinhais; Pousada Refúgio da Vila; Pousada Solar da Singuitta; Pousada Teju; Pousada Toca da Coruja; Pousada Zé Maria; Quinta da Paz - Resort; Quinta do Bucanero; Refúgio Ecológico Caiman; Rio do Rastro - Eco Resort; Ronco do Bugio - Pousada e Gastronomia; Solar da Ponte; e Solar do Império.
} 
Tabela 1. Distribuição dos meios de hospedagem associados a Roteiros de Charme por estado

\begin{tabular}{|c|c|}
\hline Estado & $\begin{array}{c}\text { Quantidade de meios de } \\
\text { hospedagem }\end{array}$ \\
\hline Alagoas & 1 \\
\hline Bahia & 4 \\
\hline Ceará & 1 \\
\hline Mato Grosso do Sul & 2 \\
\hline Minas Gerais & 5 \\
\hline Paraná & 1 \\
\hline Pernambuco & 10 \\
\hline Rio de Janeiro & 2 \\
\hline Rio Grande do Norte & 4 \\
\hline Rio Grande do Sul & 6 \\
\hline Santa Catarina & 11 \\
\hline São Paulo & 50 \\
\hline TOTAL & 3 \\
\hline
\end{tabular}

Portanto se verifica a singularidade do objeto de estudo na hotelaria brasileira.

\section{Resultados e Discussões}

Após visitas feitas às páginas exclusivas desses estabelecimentos no site http://www.roteirosdecharme.com.br, constatou-se que, dos cinquenta meios de hospedagem da Associação 46 trouxeram a palavra "restaurante", ou similar, que remete à presença de algum meio gastronômico, no item "Lazer e áreas sociais", como apresentado no Gráfico 1 e verificado no exemplo da Figura 1. 
Gráfico 1. Número de meios de hospedagem listados no site Roteiros de Charme que fazem referência à palavra "restaurante" ou similar

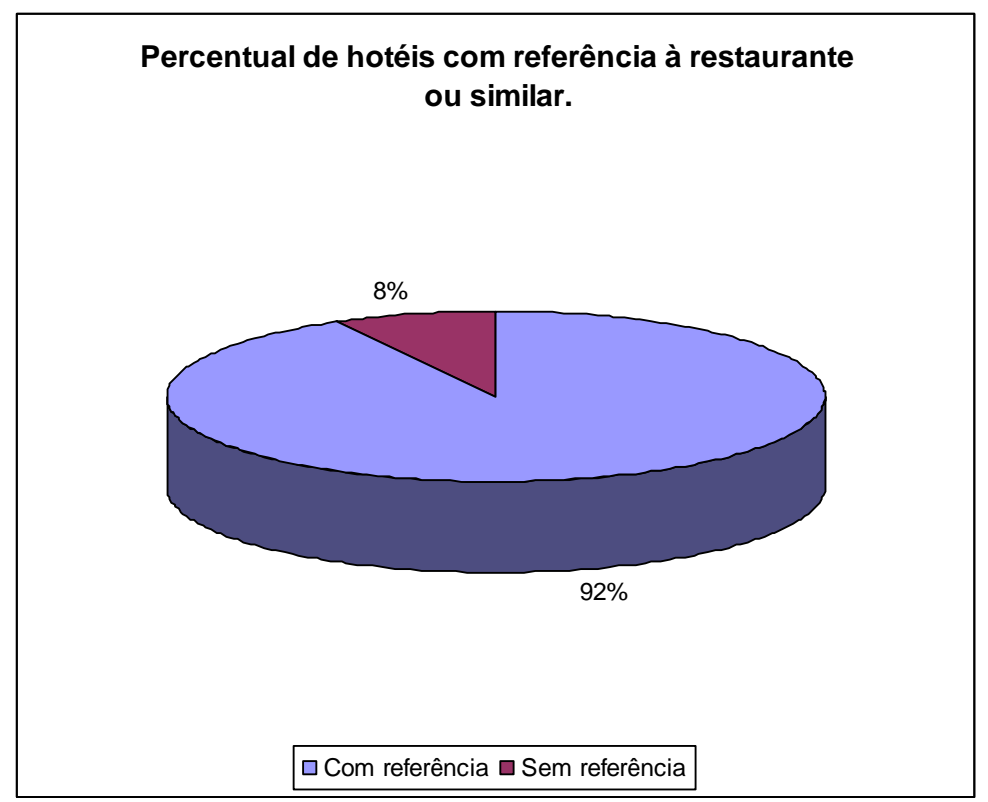

Fonte: http://www.roteirosdecharme.com.br 
Figura 1. Exemplo de página exclusiva de associado, no site

http://www.roteirosdecharme.com.br, que faz referência à palavra "restaurante" ou similar

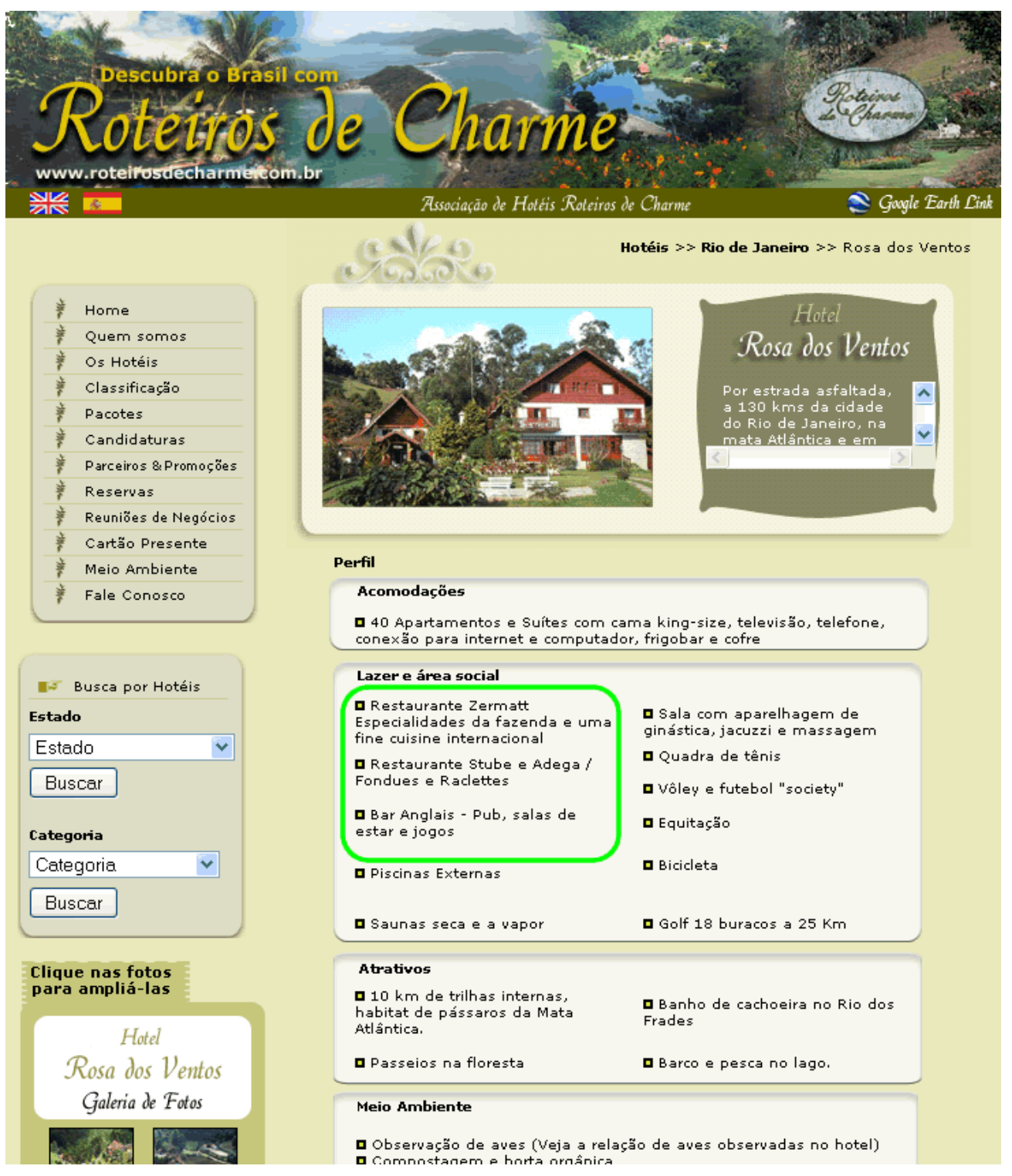

Dos meios de hospedagem pesquisados, todos têm um website próprio. Na visita a home pages (primeira página de informações), constatou-se o uso das palavras "restaurante", "gastronomia", ou similar, em 37 páginas, como apresentado na Figura 2. Em outros 13 websites, não se fez referência na página principal, mas em links, como "O hotel" ou "Atrativos de lazer". Ou seja, isso 
demonstra que todos os empreendimentos pesquisados dão destaque à gastronomia de seus estabelecimentos, como demonstrado no Gráfico 2.

Figura 2. Exemplo de website próprio de meio de hospedagem, que faz referência à palavra "restaurante" ou similar, em sua home page (primeira página de informações)

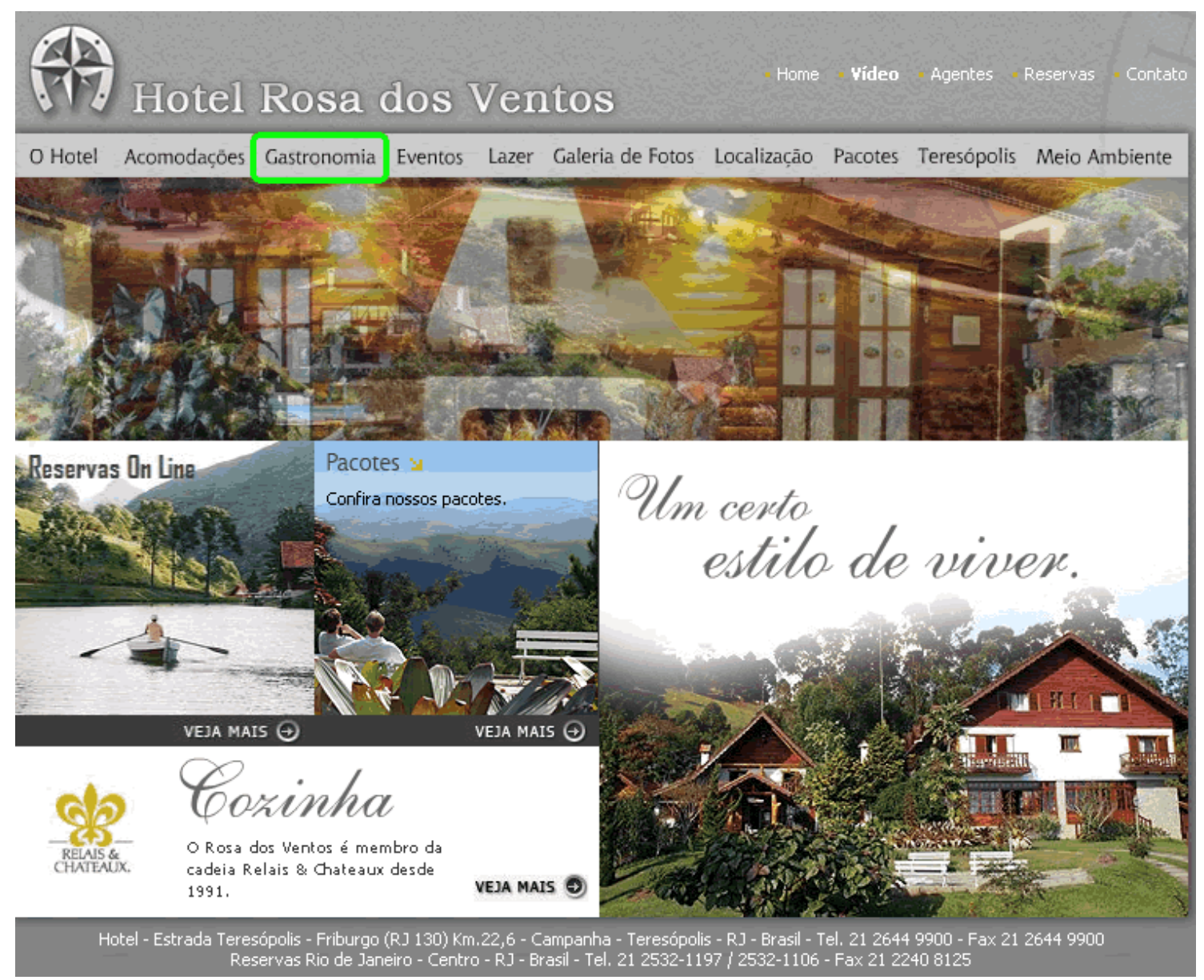

Fonte: http://www.hotelrosadosventos.com.br/pt-br/. 
Gráfico 2. Referência à palavra "restaurante" ou similar em website próprio do meio de hospedagem, associado a Roteiros de Charme por local encontrado

\section{Referência à restaurante ou similar no website do hotel por local encontrado.}

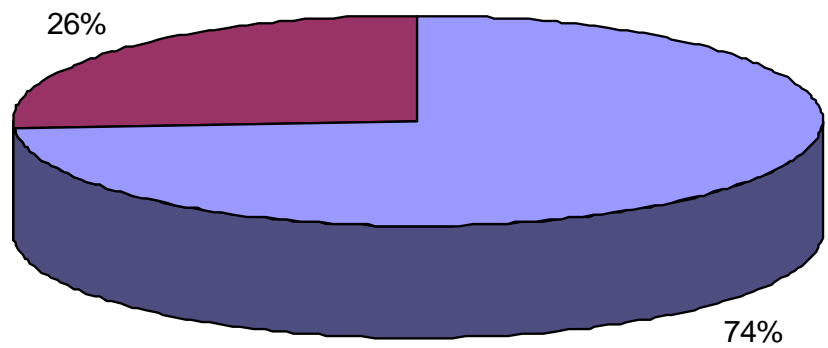

$\square$ Referência à palavra "restaurante" ou similar na home page

口 Referência à palavra "restaurante" ou similar em outros links do site

Fonte: Sites dos meios de hospedagem pesquisados (ver referências bibliográficas)

Destarte, conclui-se que a gastronomia, como um produto da hospitalidade e do entretenimento, encontra-se presente nos websites pesquisados.

\section{Conclusão}

Objetiva-se, por meio deste estudo, identificar, com base em pesquisa documental, qual a importância que, nos meios de hospedagem, se dá à gastronomia como diferencial de hospitalidade e entretenimento, de modo a ser percebida nos meios de comunicação das destinações turísticas, tendo como recorte os estabelecimentos da Associação Roteiros de Charme.

Assim, com base nas informações supracitadas, pôde-se constatar que a gastronomia, como um produto da hospitalidade e do entretenimento, faz-se 
presente e importante, do ponto de vista de divulgação, no mix de produtos e serviços oferecidos pelo meio de hospedagem, na forma virtual, pois apresenta novas possibilidades - na verdade, não tão novas, mas nem sempre bem exploradas - como formas de atração e diferenciação.

Conclui-se, ainda, que a exploração desse serviço ocorre independente do estado onde se localiza a organização. Atribui-se, portanto, à gastronomia, como manifestação cultural, um status de polo de atração de fluxos turísticos e de investimentos, representando negócios, geração de emprego, renda, além de viabilizar e universalizar a troca humana e o convívio entre culturas, costumes e hábitos.

Como limites da pesquisa, tem-se o fato da falta da constatação in loco da exploração desse diferencial, pois pode ser que a ênfase seja dada apenas no espaço virtual. Como agenda de pesquisa - ainda relacionada com a exploração gastronômica - , sugere-se: verificar a presença da gastronomia regional em meios de hospedagem; aferir a presença de clientes ("passantes") em estabelecimentos com o único propósito de utilizar os serviços de alimentos e bebidas; medir o nível de profissionalização desses serviços em empresas que utilizam a gastronomia como atrativo turístico.

\section{Referências}

ANDRADE, D. C. T. Gestão em hotelaria: o caso do Hotel Alvorada (FAEPE). Lavras, UFLA, 2004.

ANTHURIUM PARQUE HOTEL. Disponível em: http://www.anthurium.com.br/. Acesso em: 15 maio 2009.

ASSOCIAÇÃO ROTEIROS DE CHARME. Disponível em: http://www.roteirosdecharme.com.br/. Acesso em: 15 maio 2009.

BENI, M. C. Globalização do turismo: megatendências do setor e a realidade brasileira. São Paulo: Aleph, 2003.

BOYD JR., H. W.; WESTFALL, R. Pesquisa mercadológica: texto e casos. Rio de Janeiro:

Editora FGV, 1987. 
CAPIM LIMÃO - HOTEL E RESTAURANTE. Disponível em: http://www.capimlimao.com.br/. Acesso em: 15 maio 2009.

CASA DO LAGO. Disponível em: http://www.casadolago.com.br/. Acesso em: 15 maio 2009.

DENCKER, A. F. M. Métodos e técnicas de pesquisa em turismo. São Paulo: Futura, 2002.

DIAS, C. (Org.). Hospitalidade: reflexões e perspectivas. São Paulo: Manole, 2002.

FAZENDA CAPOAVA. Disponível em: http://www.fazendacapoava.com.br/. Acesso em: 15 maio 2009.

FRANCO, A. De caçador a gourmet: uma história da gastronomia. São Paulo, SENAC, 2001.

FURTADO, S. M.; PAULA, N. M.; SCHWAN, T. P. Os cursos de gastronomia no contexto do turismo: uma breve reflexão. In: SEMINÁRIO DE PESQUISA EM TURISMO DO MERCOSUL, 5,2008 , Caxias do Sul. [páginas?]. Turismo e desenvolvimento regional. Caxias do Sul, 27 e 28 jun. 2008.

GASTAL, S. O produto cidade: caminhos de cultura, caminhos de turismo. In: BARRETTO Filho, Abdon et al. Turismo urbano. São Paulo: Contexto, 2000, p. 33-42.

GOELDNER, C.; RITCHIE, B.; MCINTOSH, R. Turismo: princípios, práticas e filosofia. 8. ed. Trad. Roberto Costa. Porto Alegre: Bookman, 2002.

HOSPEDARIA ÁGUAS CLARAS. Disponível em: http://www.fazendaambiental.com.br/. Acesso em: 15 maio 2009.

HOTEL DA BOCAINA. Disponível em: http://www.hoteisdabocaina.com.br/. Acesso em: 15 maio 2009.

HOTEL DOLCE VITA. Disponível em: http://www.hotelladolcevita.com.br/. Acesso em: 15 maio 2009.

HOTEL ESTALAGEM ST. HUBERTUS. Disponível em: http://www.sthubertus.com/. Acesso em: 15 maio 2009.

HOTEL FAZENDA BOA ESPERANÇA. Disponível em: http://www.fazendaboaesperanca.com.br/. Acesso em: 15 maio 2009.

HOTEL FRONTENAC. Disponível em: http://www.frontenac.com.br/. Acesso em: 15 maio 2009.

HOTEL ORIXÁS. Disponível em: http://www.orixashotel.com.br/. Acesso em: 15 maio 2009.

HOTEL PARADOR CASA DA MONTANHA. Disponível em: http://www.paradorcasadamontanha.com.br/. Acesso em: 15 maio 2009.

HOTEL POUSADA CANTO DAS ÁGUAS. Disponível em: http://www.lencois.com.br/. Acesso em: 15 maio 2009. 
HOTEL RECANTO DAS TONINHAS. Disponível em: http://www.toninhas.com.br/. Acesso em: 15 maio 2009.

HOTEL ROSA DOS VENTOS. Disponível em: http://www.hotelrosadosventos.com.br/. Acesso em: 15 maio 2009.

HOTEL SANTA ESMERALDA. Disponível em: http://www.hotelsantaesmeralda.com.br/. Acesso em: 15 maio 2009.

HOTEL SÃO GOTARDO. Disponível em: http://www.hotelsaogotardo.com.br/. Acesso em: 15 maio 2009.

INSTITUTO BRASILEIRO DE GEOGRAFIA E ESTATÍSTICA (IBGE). Disponível em: http://www.ibge.gov.br/. Acesso em: 28 abr. 2009.

JOHNSTON, R.; CLARK, G. Estratégia de serviços. In: Administração da produção e serviço. São Paulo: Atlas. 2002

KRIPPENDORF, J. Sociologia do turismo: para uma nova compreensão do lazer e das viagens. São Paulo: Aleph, 2000.

LA HACIENDA ESTALAGEM E RESTAURANTE. Disponível em: http://www.lahacienda.com.br/. Acesso em: 15 maio 2009.

LAKE RESORT ÁGUAS DO TREME. Disponível em: http://www.aguasdotreme.com.br/. Acesso em: 15 maio 2009.

LAVILLETTE POUSADA. Disponível em: http://www.lavillettepousada.com.br/. Acesso em: 15 maio 2009.

LOOCWOOD, A.; MEDLIK S. (Org). Turismo e hospitalidade no século XXI. Trad. Eliana Keeling e John Keeling. Barueri: Manole, 2003.

MACEDO, I. S. Turismo gastronômico: análise da representatividade da gastronomia no turismo do município de Salvador/Bahia - São Paulo, 2008.

MANARY PRAIA HOTEL. Disponível em: http://www.manary.com.br/. Acesso em: 15 maio 2009.

PEDRA DA LAGUNA POUSADA E SPA. Disponível em: http://www.pedradalaguna.com.br/. Acesso em: 15 maio 2009.

PESTANA HOTÉIS - ANGRA DOS REIS. Disponível em: http://www.pestana.com/. Acesso em: 15 maio 2009.

POUSADA CRAVO E CANELA. Disponível em: http://www.pousadacravoecanela.com.br/. Acesso em: 15 maio 2009.

POUSADA DA VIGIA. Disponível em: http://www.pousadavigia.com.br/. Acesso em: 15 maio 2009. 
POUSADA DO AMPARO. Disponível em: http://www.pousadadoamparo.com.br/. Acesso em: 15 maio 2009.

POUSADA DO CAPITÃO. Disponível em: http://www.pousadadocapitao.com.br/. Acesso em: 15 maio 2009.

POUSADA DO MONDEGO. Disponível em: http://www.mondego.com.br/. Acesso em: 15 maio 2009.

POUSADA DO RIACHO. Disponível em: http://www.pousadadoriacho.com.br/. Acesso em: 15 maio 2009.

POUSADA DO TOQUE. Disponível em: http://www.pousadadotoque.com.br/. Acesso em: 15 maio 2009.

POUSADA ENSEADA DAS GARÇAS. Disponível em: http://www.enseadadasgarcas.com.br/. Acesso em: 15 maio 2009.

POUSADA ESTRELA D’ÁGUA. Disponível em: http://www.estreladagua.com.br/. Acesso em: 15 maio 2009.

POUSADA FELÍSSIMO. Disponível em: http://www.pousadafelissimo.com.br/. Acesso em: 15 maio 2009.

POUSADA ILHA DO PAPAGAIO. Disponível em: http://www.papagaio.com.br/. Acesso em: 15 maio 2009.

POUSADA LES ROCHES. Disponível em: http://www.pousadalesroches.com.br/. Acesso em: 15 maio 2009.

POUSADA PITINGA. Disponível em: http://www.pousadapitinga.com.br/. Acesso em: 15 maio 2009.

POUSADA PORTO IMPERIAL. Disponível em: http://www.portotel.com.br/. Acesso em: 15 maio 2009.

POUSADA QUINTA DOS PINHAIS. Disponível em: http://www.quintadospinhais.com.br/. Acesso em: 15 maio 2009.

POUSADA REFÚGIO DA VILA. Disponível em: http://www.refugiodavila.com.br/. Acesso em: 15 maio 2009.

POUSADA SOLAR DA SINGUITTA. Disponível em: http://www.pousadasolarsinguitta.com.br/. Acesso em: 15 maio 2009.

POUSADA TEJU. Disponível em: http://www.pousadateju.com.br/. Acesso em: 15 maio 2009.

POUSADA TOCA DA CORUJA. Disponível em: http://www.tocadacoruja.com.br/. Acesso em: 15 maio 2009. 
POUSADA ZÉ MARIA. Disponível em: http://www.pousadazemaria.com.br/. Acesso em: 15 maio 2009.

QUINTA DA PAZ - RESORT. Disponível em: http://www.quintadapaz.com.br/. Acesso em: 15 maio 2009.

QUINTA DO BUCANERO. Disponível em: http://www.bucanero.com.br/. Acesso em: 15 maio 2009.

REFÚGIO ECOLÓGICO CAIMAN. Disponível em: http://www.caiman.com.br/. Acesso em: 15 maio 2009.

RIO DO RASTRO - ECO RESORT. Disponível em: http://www.riodorastro.com.br/. Acesso em: 15 maio 2009.

RONCO DO BUGIO - POUSADA E GASTRONOMIA. Disponível em: http://www.roncodobugio.com.br/. Acesso em: 15 maio 2009.

SCHREIBER, M. D. C. J. A gastronomia teuto-brasileira em Blumenau e Pomerode-SC: como patrimônio cultural e atrativo turístico. 2006. [páginas?] Dissertação (Mestrado) Universidade do Vale de Itajaí - UNIVALI, Balneário de Camboriú, 2006.

SOLAR DA PONTE. Disponível em: http://www.solardaponte.com.br/. Acesso em: 15 maio 2009.

SOLAR DO IMPÉRIO. Disponível em: http://www.solardoimperio.com.br/. Acesso em: 15 maio 2009.

TRIGO, L. G. G. Turismo e qualidade: tendências contemporâneas. Campinas-SP: Papirus, 1998 (Col. Turismo).

VILARINHO, P.; SCORSATO, S. Marketing de destinos turísticos. Brasília-DF, MTur 2009. 


\section{Diego César Terra de Andrade}

Professor e Diretor de Ensino, Pesquisa e Extensão no Instituto Federal de Educação, Ciência e Tecnologia do Sul de Minas Gerais - Câmpus Pouso Alegre

Doutorado em Administração - Universidade Nove de Julho

Mestre em Administração - Universidade Federal de Lavras (2011)

Pós Graduado, MBA em Hotelaria - Universidade Federal de Juiz de Fora/SENAC (2006 - 770h)

Bacharel em Administração - Universidade Federal de Lavras (2005) e Licenciado em Matemática (2013) - Faculdade Capixaba de Nova Venécia

diego.terra@ifsuldeminas.edu.br

IFSULDEMINAS - Estrada do Aeroporto, 1.730 - Jardim Aeroporto - 37550-000

Pouso Alegre/MG 